\title{
Animal Rights and the Deliberative Turn in Democratic Theory
}

\begin{abstract}
Deliberative democracy has been castigated by those who regard it as exclusive, elitist, and unrealistic. As a result, it is suggested, deliberative arenas will merely reproduce inequalities, advantaging the already powerful extolling mainstream world views excluding the interests of the less powerful. Moreover, the tactics employed by those excluded social movements seeking to right an injustice are typically those which are incompatible with the key characteristics of deliberatively democracy. This paper seeks to examine the case against deliberative democracy through the prism of animal rights. It will be argued that the critique of deliberative democracy is largely misplaced because it underestimates the rationalistic basis of animal rights philosophy, misunderstands the aspirational character of deliberative theory, mistakenly attributes problems that are not restricted to deliberation but result from interest group politics in general, and ignores the educative potential of deliberation. It is further argued that this debate about the apparent incompatibility between the ideals of deliberative democracy and non-deliberative activism disguises the potential that deliberative democracy has for advocates of animal rights and, by extension, other social movements too.
\end{abstract}


Deliberative democracy began life as a radical critique of the conventional, aggregativebased, theory and practice of democracy, which, it is argued, is too open to abuse by those elites with money and the capacity to manipulate public opinion. However, deliberative democracy has, in turn, been castigated by those who regard it as exclusive, elitist and unrealistic, because of its failure to take into account a range of structural inequalities existing within contemporary liberal democracies, and its failure to recognise that there are severe psychological constraints on the capacity of individuals to fulfil the role required of them. As a result, it is suggested, deliberative arenas will merely reproduce these inequalities, advantaging the already powerful extolling mainstream world views excluding the interests of the less powerful and those expounding alternative worldviews. Moreover, the tactics employed by those excluded social movements seeking to right an injustice are typically those - involving various forms of protest and direct action - which are incompatible with the key characteristics of deliberatively democracy and are therefore deemed to be illegitimate by deliberative theorists.

One social movement to which this critique of deliberative democracy has been applied is that concerned with advocating animal rights. This article seeks to evaluate the case against deliberative democracy through the prism of this one social movement and one issue, although it is emphasised that the arguments provided have a wider resonance beyond the particular issue of animal rights. Thus, it will seek to defend deliberative democracy against the charge that it is incompatible with animal rights activism, and by so doing seeks to defend deliberative democracy more broadly. It will be argued that the critique of deliberative democracy is largely misplaced because it underestimates the rationalistic basis of animal rights activism and philosophy, misunderstands the aspirational character of deliberative theory, mistakenly attributes problems that are not restricted to deliberation but 
result from interest group politics in general, and ignores the educative potential of deliberation. It is further argued that this debate about the apparent incompatibility between the ideals of deliberative democracy and non-deliberative activism disguises the potential that deliberative democracy has for advocates of animal protection and, by extension, other social movements too.

\section{Deliberative Democracy: From Saviour to Pariah.}

The idea of deliberation has a long history in political thought (Gutmann and Thompson, 2004: 8-9) but, since the 1980s - led by the seminal work of Habermas $(1990 ; 1996)$ in particular - democratic theory has taken a 'deliberative turn' (Bohman, 1998; Dryzek, 2000: 1). Indeed, it is little exaggeration to claim that, since then, deliberative democracy has played a leading role in political theory itself. Its purchase has been the offering of a remedy, or at least a partial one, to the perceived weaknesses of traditional democracies characterised by soundbite politics, the dominance of money, poor decision-making, declining participation, increasing moral and political divisions and so forth. The academic scholarship on deliberative democracy is extensive and varied. ${ }^{1}$ Because of the volume of literature, there has been a degree of 'concept stretching' (Steiner, 2008). Nevertheless, it is still possible to elicit a number of key features shared amongst a vast majority of the exponents of deliberative democracy.

The first feature is that democracy ought not to be defined in terms of the aggregation of pre-existing preferences in a vote at elections or in a referendum, nor in terms of a reflection of the balance of competing interests within civil society, as the pluralist model has it. Rather, for advocates of deliberative democracy, collective decisions are only legitimate if they are made after reasoned and detailed discussion. It therefore focuses on the 
communicative process, being a 'talk-centric, rather than a 'voting-centric' democratic theory (Chambers, 2003: 308). Second, it is held that genuinely deliberative arenas ought to be as inclusive as possible with all points of view and social characteristics represented, and an equal chance to participate offered to all of those who are present. Inclusivity, therefore, refers to both presence and voice.

Third, during deliberation, self interest should be put aside, as should strategic behaviour designed to achieve as much as possible of a pre-existing agenda. Instead, mutual respect of, and empathy for, the arguments of others is encouraged. Fourth, the inclusive communication and social learning inherent in the deliberative process, it is suggested, leads to better decisions in the sense that they are more informed, more effective, more just and therefore more legitimate. For some deliberative democrats (for example, Estlund, 1997), the epistemic function is paramount whereas for others (for example, Gaus, 1997) the intrinsic value of deliberation, its educative function and its closer approximation to political equality, is its most important attribute.

Finally, 'a central tenet of all deliberative theory' (Chambers, 2003: 318) is that deliberation can change minds and transform opinions. The goal, at least in some particularly early - accounts of deliberative democracy, is to arrive at decisions that everyone can accept, or at least not reasonably reject. It is seen, therefore, as a useful device to tackle issues which seem to involve intractable moral conflicts (Gutmann and Thompson,1996). That is not to say that unanimity is a real prospect in most cases, and value pluralism is accepted by most advocates of deliberative democracy as a normatively justified obstacle to consensus (Chambers, 2003: 321; Dryzek, 2010: chapter 5; Friberg-Fernos and Schaffer, 2014: 100; Gutmann and Thompson, 2004: 26-9; Mackie, 2006: 290). As a result, the aggregation of preferences may well still be necessary as an end-point. However, even if there is still disagreement, collective decisions made after deliberation are regarded as more 
legitimate than the mere aggregation of preferences, not necessarily or not just because of the decisions made, but because of the deliberative procedure followed which engenders mutual understanding. It involves a sense, that is, that all the views of participants are taken seriously and that everyone tries to empathise with the views of others. For Gutmann and Thompson, 1996: 3, 83-5), for instance, deliberation should aim at an 'economy of moral disagreement' in the sense not just that the participant's substantive positions have moved closer together, but that there is a greater acceptance of the terms of difference and disagreement.

Not surprisingly, perhaps, deliberative democracy has met with some strong criticisms. One significant problem, it is argued, is that, without some fundamental reforms to the balance of power amongst competing interests in contemporary liberal democracies, deliberatively democracy merely reproduces existing inequalities, advantaging the already powerful (Shapiro, 2005: 24). Thus: 'By insisting that parties to deliberation not depart from public reason, they...propose to rigidify some of the structural disadvantages that marginalized groups confront' (Medearis, 2005: 64). The inequalities referred to are based, in part, on finance, but also go wider, and include the type of communication valued by advocates of deliberative democracy and the possibility of discourse hegemony constraining what is discussed in deliberative forums. Thus, a common complaint is that deliberative democracy advantages a particular form of rationalistic and dispassionate communication which benefits some - the well-educated and well-spoken - over others who may favour speech which is emotional and passionate (Sanders, 1997; Young, 1996; 2000; 2001).

Another, related, source of inequality is ideological hegemony, in which the views expressed in political arenas - and, by definition in deliberative arenas too - are necessarily limited so as not to challenge the dominant relations of power (Lukes, 2005). As Young (2001: 685) points out, activists confronted by a deliberative setting will be suspicious on the grounds that 'the majority of participants...will be influenced by a common discourse that 
itself is a complex product of structural inequality'. Deliberative democracy therefore lacks a theory of ideology to counter the dangers of a hegemonic discourse. For social movements intent on radical change, then, participation in deliberative forums is unproductive, co-opting the 'energy of citizens committed to justice, leaving little time for mobilizing people to bash the institutional constraints and decision-making process from the outside' (Young, 2001: $682)$.

Because of these inequalities, critics of deliberative democracy claim, some groups may have to engage in activities - such as direct action - to get their voices heard and to challenge a dominant discourse. However, it is further argued, these types of activities are incompatible with the methods prescribed by deliberative democrats. As a corollary, by denying the legitimacy of such tactics, it is claimed that deliberative democracy takes insufficient account of the inequalities of power in existing liberal democracies, inequalities which the non-deliberative tactics of many social movements are designed to address. As Young (2001: 675) writes: 'The deliberative democrat who thinks that power can be bracketed by the soft tones of the seminar room is naive'.

Another argument against deliberative democracy is that it, rather naively, chooses to neglect the fact that, as psychological studies persuasively suggest, most of our moral and political decision-making is based on non-rational factors (such as habit, emotions, and culturally adopted meanings). Generated in such a way, these beliefs are unlikely to be altered through reasoned arguments. Participants in a deliberative arena may therefore accept a reasoned argument and yet still cling to their previous nonrationalistic beliefs. Ryfe (2005: 56) goes as far as to say that deliberation 'represents a disturbance of every-day reasoning habits' in the sense that it ignores the evidence which suggests a propensity for individuals to take information short cuts and to 


\section{habitually cling to long-held positions irrespective of evidence which seems to challenge their validity (see also Mutz, 2008: 533-5 and Rosenberg, 2014: 101-12).}

\section{Deliberative Democracy and Animal Rights Activism}

These critiques of deliberative democracy can, and have been, made in the context of animal rights activism. The animal rights movement is the classic example of an outsider. Its objective - the complete abolition of the use of animals for human benefit - is far removed from current practice - and, for the most part, public opinion. The animal rights movement is faced by very powerful interests - those representing agribusiness and pharmaceutical companies in particular - and a dominant discourse which suggests that the use of animals (provided this use is as humane as possible) is morally unproblematic. It is possible, of course, for the animal rights movement to seek compromise. However, a significant portion of activists are unwilling to compromise and dilute their moral purity believing that its adversaries are unresponsive to mere argumentation. As a result, many of the animal rights movement's adversarial and conflictual tactics are, it is argued, incompatible with the consensual and accommodation behaviour required by deliberative democracy (Humphrey and Stears, 2006).

Deliberative democracy is therefore incompatible with animal rights activism, it is argued, insofar as it denies the legitimacy of any outcome produced by adversarial and conflictual activism. Given the structural inequalities that the animal rights movement is faced with, it is argued, activists should 'not be expected to restrain their efforts by accepting the behavioural and dispositional limitations urged upon them by the theorists of deliberative democracy' (Humphrey and Stears, 2006: 417). D'Arcy (2007: 7) concurs with this judgment. Insofar as the animal rights movement relies crucially on adversarial and strategic 
actions, then deliberative democracy suffers from 'a fatal defect that decisively undermines its viability'.

For Humphreys and Stears (2006), animal rights activism routinely engage in two tactics that are particularly at odds with deliberative democracy. The first of these is described as cost levying (405-8). This is activity which increases the cost and/or decreases the benefits associated with conduct opposed by the activists. In the case of the animal rights movement, cost-levying would include activities such as promoting consumer boycotts, negative publicity campaigns and, at the more extreme end, damage to property and the intimidation of those involved, or associated with, organisations that use animals. Such activity is, ostensibly at least, at odds with the emphasis that deliberative democrats put on reason and persuasion. That is, cost-levying works by altering behaviour through the costs incurred of not doing so.

The second strategy pursued by animal rights activists at odds with deliberative democracy is the exaggeration of moral disagreement through the use of polarizing rhetoric (Humphreys and Stears, 2006: 408-12). These activities are not designed to win opponents over by reasoned arguments or to attempt to narrow the gap between positions - the raison de' etre of deliberative democracy - but to maximise the differences between activists and their rivals. One example of this kind of strategy is to compare the killing of animals with the holocaust. Such a comparison, whatever its intentions, has the effect of demonising adversaries thereby making any reasoned conversation with them impossible. It is exactly the opposite of Guttman and Thompson's (1996) deliberative recommendation that those whose views differ should aim at an economy of moral disagreement.

\section{The critique, that humans do not have the capacities to cope with the} rationalistic demands of deliberation, can also be illustrated by reference to issues 
involving animal ethics. Thus, participants in a deliberative arena may accept an animal ethics argument (or any other ethical argument for that matter) and yet still cling to their previous non-rationalistic belief. A participant may, for example, be able to follow and concur with the closely-argued case against eating meat, but habit and custom may prevent the change in behaviour that ought to be the rational response.

\section{Deliberative Democracy, Non-deliberative Activism and the Animal Rights Movement}

This paper seeks to argue that the alleged incompatibility between animal rights activism and deliberative democracy can be exaggerated. In the first place, it should be pointed out that whilst some animal rights activism is, superficially at least, undoubtedly incompatible with deliberative democracy, much of is not. The animal rights movement engages in a great deal of consciousness raising, the purpose of which is to influence, educate and transform opinions (D'Arcy, 2007: 2-3). It is no accident that the contemporary animal rights movement has grown up on the back of sustained attempts by academic philosophers to provide a reasoned justification for regarding animals as morally considerable (see, for instance, Regan, 1984 and Singer, 1990). In fact, so rationalistic has the movement been that there are some, particularly from the care-ethic tradition, who argue that the movement is too rationalistic and ought to pay more attention to values such as caring, compassion and sentiment (Donovan, 2007).

It is the case, however, that the tactics - of cost-levying and polarising rhetoric identified by Humphreys and Stears are common tactics within the animal rights movement and are, superficially at least, incompatible with the demands of deliberation. A number of responses can be made to this apparent disjuncture between deliberative principles and the tactics of the animal rights movement. In the first place, critics fail to recognise that 
deliberative democracy is a normative aspiration which 'challenges political reality' (Thompson, 2008: 499). No genuinely deliberative political system exists anywhere. It is, therefore, an ideal theory (Gutmann, 1996: 343). Many deliberative theorists, it should be noted, recognise that a genuinely deliberative political system requires a narrowing of the inequalities currently present in the political system and that this may require significant social and economic change (see, for instance, Bohman, 1996: 140; Cohen, 1988; Cohen and Rogers, 1983; Gutmann and Thompson, 1996, Chapters 6-9; Pettit, 1999: 194).

The aim is for deliberative forums to be inclusive and egalitarian, containing all relevant interests who must be given an equal chance to participate. In an unequal society, deliberative exercises should aim at bracketing inequalities, and, as Gutmann and Thompson (2004: 42-3) point out: 'Deliberation is a more promising way of dealing with injustice than the usually available alternatives, such as...bargaining among interest groups (which usually reproduce the prevailing inequalities)'. It is possible to envisage postponing deliberative democracy until a more equal society is created. Such a conclusion, though, is utopian. We can agree here with Elstub (2014: 195) when he writes that 'deepening democracy within the structural constraints of liberal democracy is still a worthy enterprise, and can, indeed, contribute to overcoming these structural constraints'. It is asking too much, however, for inequalities to be organised out of existence. Ultimately, what deliberative theory seeks to do is to ask what would a genuinely deliberative political system look like and how would it operate? In this sense, deliberative theory 'provides the normative basis from which an imminent criticism of the failings of putatively deliberative institutions can proceed' (O'Neil, 2002: 259).

Critics of deliberative democracy also exaggerate its rigidity. For example, although, as we saw, a common criticism of deliberative theory is that it advantages a particular form of rationalistic communication which benefits some over others, there is no reason - as many 
deliberative theorists have conceded (Gutmann and Thompson, 1996: 136) - why alternative forms of communication (such as rhetoric, storytelling, testimony and greeting) cannot also be permitted within deliberative forums. This represents a revision, rather than abandonment, of deliberative democracy (Talisse, 2005: 424). Alternatively, there is nothing in deliberative theory which precludes representatives from within the ranks of less eloquent groups to speak on the group's behalf (Guttman and Thompson, 1996: 133).

In addition, because many deliberative theorists do recognise that inequalities in political power can have a crucial bearing on the quality of deliberation, many accept that, in a non-deliberative polity, non-deliberative activism is justified as a means of addressing political inequalities (Gutmann and Thompson, 1996: 135; Gutmann and Thompson, 2004: 51; Smith, 2004; Bohman, 1996: 140; Pettit, 1999: 194). This acceptance of the need for nondeliberative activism is not a criticism of deliberative democracy as such, but rather a recognition that a genuine deliberative political system cannot exist without greater inclusivity. It should also be noted that, even those who have criticised the constraints of traditional deliberative democratic theory, have not rejected deliberative democracy wholesale but have adopted it to allow non-deliberative activism and non-formal means of communication. Dryzek (2000: v-vi), for instance, distinguishes between deliberative and his preferred theory of 'discursive' democracy, the latter denoting a more edgy, critical and less accommodating doctrine than the gentlemanly and calm demeanour portrayed by the former. Similarly, Young (1996: 124) describes her preferred version of a discussion-based theory a 'communicative' rather than a deliberative theory of democracy, 'to indicate an equal privileging of any forms of communicative interaction where people aim to reach understanding' as well as an acceptance of difference rather than a desire to transcend it.

Applied to the issue of animal rights, then, we can say that - whilst it is true that at least some, adversarial and confrontational, animal rights activism is incompatible with 
deliberative democracy - the tone of such activism - if not some of the more extreme versions involving actual violence (Hadley, 2015) - is entirely justified whilst the animal rights movement is so disadvantaged in the current system of interest group politics. More to the point, this activism can be justified by advocates of deliberative democracy precisely because this system does not meet the requirements of a genuinely deliberative politics. Indeed, it may be that adversarial and confrontational activism helps to ensure that the objectives of the animal rights movement are brought to public attention, and would therefore be treated with respect in any future deliberative political system (D'Arcy, 2007: 12-13). For many advocates of deliberative democracy, then, the use of non-deliberative means to achieve deliberative ends is entirely justified.

One dimension of political inequality that is particularly relevant to the debate about the treatment of animals is the ideological hegemony possessed by those powerful interests with an interest in the continued exploitation of animals (Nibert, 2002; Torres, 2007). The abolitionist animal rights paradigm is culturally and socially unacceptable for most people. The dominant non-abolitionist paradigm, which regards it as entirely normal for animals to be used for human benefit, may well be a product of the role played by powerful vested interests. More certain is the role they have played in shaping the moral and political agenda. Thus, the agribusiness industry, through advertising and other means of communication, seeks to disguise the reality of the modern industrialised 'factory' farming of animals. Likewise, the pharmaceutical industry seeks to persuade the public that animal experimentation is always vital for medical research (despite much evidence to the contrary) (see, for example, Sharpe, 1988).

The dominant discourse about animals undoubtedly affects the terms of deliberative debate, and is a further illustration why greater political equality is necessary before a genuinely deliberative environment can be achieved. Many deliberative theorists, though - as 
we have seen - would accept this conclusion. Likewise, it is not clear why an account of ideological or discourse hegemony represents a challenge to deliberative democracy in particular, as opposed to being a critique of the existing arenas of interest group and electoral politics in general. Indeed, deliberative democracy may have a better chance of countering a dominant discourse since it is designed to put all arguments - including the dominant discourse - to a reasoned test in an environment in which the influence of alternative means of communication - such as the media - can be reduced. As Fishkin (2009: 6) notes: 'Efforts to manipulate public opinion work best with an inattentive and/or uninformed public'. Thus, a mere aggregation of pre-existing preferences, without a deliberative element, is more likely to be shaped by the dominant discourse than a genuinely deliberative decision-making arena. Indeed, there is some evidence, provided below, that deliberation can neuter, to some extent, the prevailing dominant discourse about animals.

Deliberative democracy is not, then, inconsistent with 'the demand for the sort of broad, transformative democratization of existing social, economic and political institutions that would equalise power relations' (Medearis, 2005: 74). Indeed, it may be a prerequisite for genuine deliberative democracy to take place. However, this radical project compliments the role of deliberative democracy rather than replacing it. Even with perfect democratic inclusion there will still need to be decisions to make, and conflicts to manage and resolve. This is particularly the case when the issue involves moral conflict rather than the distribution of economic resources.

Because inequality, and lack of inclusiveness, is unlikely to be removed from the interest group universe, it might be argued that a genuine deliberative democracy is impossible of realisation, at least at the present time (Sanders, 1997; Walzer, 1999). Given this, it might be possible to model a nonideal version of deliberative democracy whereby socalled 'deliberative activism' (Fung, 2003) - activism aimed at getting a hearing for a social 
movement's concern within deliberative arenas - is legitimate, and may remain so whilst the nonideal circumstances prevail. This, then, would provide a way of reconciling nondeliberative activism with the principles of deliberative democracy. In this scenario, though, activists must depart from deliberation with reluctance, and only in order to further the values underlying deliberation (Fung, 2003: 402-4).

As for the argument that deliberative democracy is unrealistic because of the psychological limitations of the participants, two main responses are particularly important. In the first place, as indicated above, there has been an internal critique of rationalistic animal ethics from within the care ethic school, exponents of which argue that the animal rights movement is too rationalistic and ought to pay more attention to values such as caring, compassion and sentiment (Donovan, 2007). In other words, not all animal ethics is necessarily dependent merely on rationalistic arguments. The same, of course, applies to many other issues which have suffering and justice-claims at their core. More to the point, as we have seen, too, many deliberative theorists have accepted that deliberative communication should not give precedence to rationalistic and dispassionate speech over that which is emotional and passionate.

Of course, whilst compassion and emotion are not necessarily incompatible with rationality, habitual behaviour is more difficult, if not impossible, to reconcile with the demands of deliberative democracy. One might respond by pointing out that deliberative democracy, again as indicated above, is an aspiration. It assumes that participants, schooled in the superficiality of conventional aggregative democracy, may well struggle to cope with the greater demands of deliberation. Nevertheless, as Mill (1972: 347-8) pointed out in the context of political participation more broadly, those engaging in deliberation are likely to get better at it the more they do of it. If, on the other hand, the critique is saying that the non-rational basis of belief systems is 
immutable, a matter of capacity rather than skill (Rosenberg, 2014: 108), then the prospects for effective deliberation appear bleaker. However, the immutability claim is arguably much more difficult to sustain.

\section{Animal Rights Activism in a Genuinely Deliberative Political System}

Fung's non-ideal model of deliberative activism is only valid, of course, whilst a genuine deliberative democracy does not exist. But what if a genuinely deliberative political system was possible? The fact that to count as a genuinely deliberative political system there would have be inclusivity - where holders of all views are given an equal say, where arguments couched in self-interest are discouraged, where respect and empathy for the views of others are encouraged - suggests that animal rights activists, as well as those from other social movements, would not be disadvantaged.

In this scenario, of a genuine deliberative political system, would participation in it by social movement activists such as those concerned about animal rights become morally obligatory? Would there no longer be any justification for adversarial and confrontational activism? It should be noted that deliberative democracy remains a procedure (a theory of agency), and as such there can be no guarantee that it will produce the substantive outcomes desired by social movement, such as those advocating animal rights (although there is some evidence that it might move them closer to their goal - see below). What ought animal rights advocates to do then? Should they give up on employing additional, non-deliberative, tactics which might help them to move further towards their goal?

Animal rights advocates, it should be said, are unlikely to accept the consensus, or at least the recognition and acceptance of difference, that deliberative forums aspire to because 
that does not include the meeting of their abolitionist goals. Indeed, this is likely to preclude them from agreeing to deliberate in the first place. In this sense, fundamentalism is not really compatible with deliberation. As Simon (1999: 50) points out in the context of another issue: 'many minority students and academics regard the demand to deliberate over issues of racial justice, notably affirmative action, as offensive or oppressive. For them, merely to treat such questions as open to debate is a personal assault'. Insofar as contemporary politics is characterised by a clash of fundamentalisms, then, deliberation may be an unrealistic aspiration. Shapiro (1999: 30) articulates the problem astutely when he notes that asking a fundamentalist to participate in deliberative forums 'would look as though she were being told that it is fine to be a fundamentalist so long as she abandons her fundamentalism'. As a result, the only fundamentalists who are likely to be amenable to deliberation are 'fallibilist democrats' which, for Shapiro (2005: 26) 'is an empty class, destined to remain uninhabited'.

There is no definitive answer to the question about what attitude to deliberation social movement activists, whether concerned about animal rights or anything else, can realistically, or ought to, adopt. On the one hand, it can be argued that pursuing non-deliberative tactics is justified for any social justice movement because of the moral urgency perceived to be involved (Hendriks, 2011: 5). On the other, to complain that deliberation will not bring about the desired objectives of animal rights activists 'is to complain about democracy itself, and not about deliberation as a procedure' (Miller, 2002: 215). Provided that all perspectives on an issue are raised and discussed - which deliberative democracy requires - an outcome which rejects some of them cannot be regarded as undemocratic. Clearly, the gap - between the abolitionist goals of the animal rights movement (the end of all uses of animals for food, entertainment, and scientific procedures) and present practice - is so wide that it can be asked whether the promise of deliberative democracy is something that animal rights advocates cannot afford to ignore. 
Attention should be drawn here to a feature common to a social movement activist's position that is arguably never justified. This is a level of epistemic arrogance that advocates of deliberative democracy rightly, it seems to me, seek to challenge. A key characteristic of deliberative democracy is the insistence that participants are willing to listen to others, to try to empathise and understand their opponents point of view. The activist, by contrast, tends to think that 'those who oppose him are either the power-hungry beneficiaries of the unjust status quo or the inattentive and unaware masses who do not "think seriously" about the injustice of the institutions that govern their lives and so unwittingly accept them' (Talisse, 2005: 428). Given the on-going, and unresolved, academic debate about questions of justice in general, and animal rights in particular, a degree of 'epistemic modesty', enshrined in the practice of deliberative democracy (Talisse, 2005: 429-30), might be in order for animal rights activists. This is particularly the case when it is realised that there are those, on the other side of the debate, who are equally convinced that animal exploitation is not only morally legitimate but, particularly in the case of animal experimentation, morally obligatory.

\section{Is Deliberative Democracy Beneficial to Animals?}

Even if we reject the claim that deliberative democracy is incompatible with the tactics employed by the animal rights movement, this still does not mean that it is particularly advantageous for animal rights activists to commit themselves to participating in deliberative arenas. Ultimately, as I pointed out above, the relationship between democrat procedures and desired outcomes remains contingent, so there is no certainty that the deliberative democratic procedure is going to produce outcomes that are desirable for animal advocates. In any case, from an impartial standpoint, the case for deliberative democracy does not, of course, depend on how far it does so. However, some political theorists have claimed that a deliberative form 
of democracy is likely to produce more ecologically desirable outcomes than the conventional aggregative form of democracy (Dryzek, 1987, 1990; Eckersley, 2000; Goodin 2003; Smith, 2003), and it is worth speculating how far this assertion is valid in the case of debate and decision-making in the case of animals.

The promise of deliberative democracy for animal advocates (as it might be for other social movement activists) might be considerable if it is the case that it can lead to a transformation of views in their favour. At present, animal advocates can make the claim accurate or not - that, on at least some issues, public opinion is supportive of greater protection for animals than is presently allowed for by current legislation and regulations. Invoking deliberative democracy, however, allows us to go one step further. The claim here is not just that we should compare policy outcomes with an aggregation of individual preferences in opinion polls. Rather, we should be comparing the present legislative and administrative regimes governing the treatment of animals with genuinely informed public opinion mediated through deliberation. As Fishkin and Luskin, (2000: 19) put it: 'In contrast to ordinary polls, showing public opinion as it is, these deliberative microcosms attempt to show public opinion as it would be if its members learned, thought, and talked more about the issues'.

The case for regarding a deliberative form of democracy as conducive to environmental protection is based on a number of factors, and these can be reviewed to assess their efficacy for animal protection. It is argued, firstly, that deliberative democracy encourages participants to be open to the views of others, to listen to what they have to say and empathise with their point of view. This conclusion is embellished by the inclusive demands of deliberative democracy, whereby all positions in the (in this case animal ethics) debate have to be present and heard. One can see how the views of those who seek to protect animals (including those who seek to abolish the use of animals) would probably get a better 
hearing in an inclusive deliberative environment than in traditional campaigning, and this might lead to a shift in views, or at least an 'economy of moral disagreement' (Gutmann and Thompson, 1996: 3, 83-5).

One can see, too, how the empathy facilitated by deliberation might be extended beyond humans to include other species. Goodin $(2003 ; 2005)$ provides one model whereby deliberation 'within' (because he envisages an 'internal reflective' mode of deliberation occurring within the minds of individuals as an alternative to an 'external collective' mode) allows for the interests of the excluded and the mute (future generations, nature and animals) to be promoted by being encapsulated or incorporated into the interests of the participants (through 'empathetic imagining'). The interests of nonhumans, for Goodin then, can be internalized and represented by humans who become sympathetic to them through this process of internal reflection. Goodin's emphasis on the capacity of deliberative democracy to encourage empathy is linked to the supposed 'moralizing effect' (Niemeyer, 2004, p. 347) of deliberation. That is, genuine deliberation involves the advancement of arguments by citizens about what is right, and in the general or public interest, and not about what is in the self-interests of participants. One can contrast genuine deliberation here with the dominance of powerful vested interests in traditional interest group politics. Shifting the debate from interests to generalizable interests and values, it might be argued, is likely to benefit animals given that the human espousal of animal protection is an altruistic cause, not directly benefiting (at least economically) the human deliberators.

However, even if the ability of deliberation to minimise or remove the influence of self-interest (a claim that is by no means clearly established) is assumed to be the case, the dichotomy suggested - between moralizing animal advocates and selfish advocates of animal exploitation - is too simplistic. For one thing, the consideration of non-human interests 'might be at odds with generalizable human interests' (Eckersley, 1995: 179). For example, whilst it 
is undoubtedly true that the use of animals in scientific research does produce enormous financial benefits for economic actors - pharmaceutical companies in particular - and therefore serves their partial interests, there is also a public health benefit which (providing that one accepts the empirical claim that using animals to develop and test drugs does actually work) arguably transcends the self-interest of those involved in the practice.

It is clear, then, that, as Eckersley (1995: 179) asserts, there are doubts about the extent to which deliberative democracy can 'secure the protection, or at least ensure the systematic consideration, of non-human interests that might be at odds with generalisable human interests'. Because of this, Eckersley advocates the constitutional protection of nonhumans. An alternative which sticks with deliberative democracy is to dispense with an anthropocentric model of democracy by finding a way to represent the interests of animals, independently of those of humans, within deliberative forums. One device would be to utilise Goodin's idea of 'empathetic imagining'(discussed above), whereas another would be to institutionalise the representation of non-humans through the placement of guardians whose role would be to represent the interests of animals even when they clash with human interests (Eckersley, 1995: 179).

\section{Animals and the Epistemic Function of Deliberative Democracy}

The case for the efficacy of deliberative democracy is also based on the claim that the debate and reflection involved in deliberation has an epistemic function, eliciting greater understanding of an issue thereby reducing the negative influence of the media and vested interests (Cohen, 1986; Estlund, 1997). This is why the deliberative approach is seen as a prerequisite for the transformation of views which is claimed to be one of its chief strengths. Of course, in terms of the issue under review here, the assumption is that animal advocates 
are right about what they say and that extensive deliberation is bound to reveal this. One can see how this might work in cases where issues are largely dependent upon facts. It is true that the 'cost' of acquiring information on an issue is reduced within a deliberative framework (because it is provided as part of the process), and equally true that this information is provided without the distortions of the media and vested interests. Facts do play some part in the animal ethics debate. The claim that animal experimentation does produce significant human benefits, for instance, can be put to a rigorous test within a deliberative arena, and, in addition, it is plausible to claim that attitudes to factory farming can be influenced by information about exactly how animals are kept within intensive husbandry systems, and scientific evidence on the impact on them of confinement.

There is evidence from case studies of actual deliberative exercises involving animal issues that the provision of factual information has had an impact on the participants. In one case (the WQ project ${ }^{2}$ ), for instance, the aim of the citizens' juries set up as part of the exercise was to assess citizens' response to the farm animal welfare protocols drawn up by animal welfare scientists. It was reported that some jurors were 'quite shocked and surprised' by the reality of intensive animal agriculture, and all of the members of the Italian jury, and the vast majority of the UK jurors, admitted they were not aware of the sheer extent of intensification. In particular, they were shocked about the stocking densities in broiler sheds, and the short life-spans of broiler chickens (Miele, Veissier, Evans and Botreau, 2011: 113).

Although we do not know if there was a shift in opinion as a result of deliberation, because their views at the outset of deliberation were not measured, the jurors in general were fully supportive of strong animal welfare measures and they were not convinced that the protocols developed by animal welfare scientists went far enough. In particular, they were critical of the proposal that, when measuring the quality of animal welfare in any particular farm unit, very low scores in one area (such as housing) could be compensated for by high 
scores in other areas (such as nutrition). Moreover, contrary to the initial protocols, most jurors were also adamant that the classification 'excellent welfare' should only be used in relation to extensive systems with outdoor access for the animals (Miele, Veissier, Evans and Botreau, 2011: 114).

In the case of those deliberative exercises involving the issue of xenotransplantation, too $^{3}$, participants were generally hostile to the use of animal organs, preferring instead to recommend other public policy goals such as schemes to encourage organ donation and health promotion campaigns to reduce the demand for organs. There was a 'consistent lack of support' for xenotransplantation in the so-called Deliberative Mapping Project, and it was the worst performing option (out of nine) across all of the Citizens' Panels (Eames, Burgess, Davies, Mayer, Staley, Stirling, Williamson, 2004: 6; 30-6). Similarly, Participatory Technology Assessment (PTA) exercises in the Netherlands and Canada recommended a moratorium on xenotransplantation, whereas a significant minority in the Swiss PTA did so too (the majority opting for regulation) (Griessler, 2011: 38).

There is some evidence that opinion against xenotransplantation hardened when deliberators were exposed to factual information about the consequences for animal welfare, as well as the health risks. In the Canadian PTA, for instance, as the participants learnt more 'they became less accepting of xenotransplantation' (personal e-mail from Edna Einsiedel, 10 March 2014). This was confirmed in the Deliberative Mapping Project too where many held a negative view of xenotransplantation from the start but it also 'suffered significant negative shifts in performance' particularly after the joint workshop when members of the Citizens' Panels were exposed to the views of the experts (Eames, Burgess, Davies, Mayer, Staley, Stirling, Williamson, 2004: 39).It was true, too, that in most cases animal welfare played an role in determining the hostility of deliberative forums to xenotransplantation. In the Swiss case, for instance: 'A significant majority of the panel supported the statement that the 
breeding conditions of "source animals" would not at all meet requirements of speciesappropriate animal husbandry' (Griessler, 2011: 40). However, animal welfare was never the only, or the most important, issue in any jury. Rather, public health concerns (the risk of uncontrollable infection being prominent) tended to be of most concern, followed by concerns about the ethical implications of crossing the species barrier, and doubts about the feasibility of xenotransplantation).

What should be made of this empirical evidence? In the first place, insofar as the claim about the impact, in terms of changing opinions, of full, and unmediated, provision of information is true - and there is some evidence for it in addition to the examples provided above (see, for example, Barabas, 2004; Button and Mattson, 1999; Elstub, 2014, p. 179; Fishkin, 2009: 26-37, 84; Goodin, 2008, pp. 38-63; Kuper, 1997; Luskin et. al., 2002; Petts, 2001: 220; Sunstein, 2008: 97) - it should be pointed out that this can be separated from the deliberation process itself. ${ }^{4}$ That is, one could endeavour to provide comprehensive and balanced information on an issue without requiring those making a decision to then deliberate about it. It is certainly the case that, in so far as mini-publics have resulted in preference change, it is difficult to prove that it has occurred as a result of actual deliberation as opposed to the provision of information (Elstub, 2014: 179). It is also the case that if it can be shown that a 'correct' assessment of comprehensive information is more likely to emerge from a panel of experts, then - if the epistemic function of deliberation is all we are concerned about - we would be duty bound to prefer this process over democratic deliberation (Freeman, 2000: 387; Lafont, 2006: 8-9).

More significantly, the debate about the moral status of animals (and many other issues too) is not, of course, entirely, or even mainly, dependent upon facts. Facts are rarely, if ever, decisive in a normative debate where intractable moral conflicts, represented by incommensurable frames, are unlikely to find an easy resolution (Button and Mattson, 1999: 
622). Thus, for example, even if animal experimentation does produce significant benefits to humans - vital, life saving, benefits even - an animal rights advocate would still regard the use of animals as illegitimate, regarding the benefits as ill-gotten. ${ }^{5}$ There is some arrogance, then, involved in the claim that were people in possession of all the - empirical and normative - information then they are sure to be converted to an animal protection point of view let alone an animal rights cause, the latter involving a commitment to the abolition of animal exploitation and not just its reform. There is no evidence from the empirical cases studies mentioned above, for instance, that the provision of information and the deliberative process led to any transformation in the worldviews of the participants. No participant was converted to the animal rights cause as a result of deliberation and, similarly, the small minority of participants who declared a commitment to animal rights at the beginning were not persuaded to amend their position.

\section{Conclusion}

By considering deliberative democracy in the context of a particular social movement issue, this article has argued that deliberative democracy can be defended against the charges that it is inconsistent with the tactics employed by social movements such as the one that seeks to promote the rights of animals, and that it is unrealistic given the constraints of human psychology. Such a conclusion underestimates the rationalistic basis of animal rights activism and philosophy, misunderstands the aspirational character of deliberative theory, mistakenly attributes problems that are not restricted to deliberation but result from interest group politics in general, and ignores the educative potential of deliberation. It is quite another thing, however, to claim that participation in deliberative forums will inevitably lead to a more positive attitude to the protection of animals, let alone result in the acceptance of an 
animal rights agenda. There is some evidence that the provision of detailed information of the way animals are actually treated does have the capacity to shift opinions, but it is not clear how important the role of deliberation, as opposed to exposure to information, is responsible.

Ultimately, deliberative democracy remains a procedure, whereas social movement agendas, such as that promoted by animal rights advocates, represent a substantive value. The relationship between democrat procedures and desired outcomes, therefore, remains contingent, so there is no certainty that even a deliberative democratic procedure is going to produce outcomes that are desirable for social movement advocates. However, such advocates have to, and presumably prefer to, participate in a democratic environment. Here, there is some evidence to suggest that a genuinely deliberative political system will be more beneficial to them than an aggregative version which magnifies the inequalities which disadvantage them. In the meantime, deliberative theory does not prohibit social movement activists, such as those concerned with promoting animal rights, from pursuing non-deliberative tactics.

\section{Notes}

1. The literature on deliberative democracy is too extensive to cite in full. Early crucial texts were provided by Habermas, 1990,1996. The fact that there are so many edited collections on the subject is indicative of its resonance in political studies. The most notable are: Benhabib, 1996; Besson and Marti, 2006; Bohman, and Rehg, 1997; D’Entreves, 2002; Elster, 1998; Elstub and McLaverty, 2014; Fishkin and Laslett, 2008; Macedo, 1999; Saward, 2000.

2. The Welfare Quality (WQ) project was an EU-funded exercise which sought to ascertain societal views in drawing up a protocol for assessing animal welfare on farms and at 
slaughter plants (Miele, Veissier, Evans and Botreau, 2011). This was achieved through the creation of almost 50 focus group discussions in a variety of EU member states, and citizens' juries in Italy, the UK and Norway. The latter consisted of 10-12 people representing different sides of the debate (vegetarians, consumers on a budget, health conscious consumers, environmentally aware consumers, halal or kosher eaters, 'mainstream' consumers and so on) who met on a weekly basis for a number of sessions lasting for two hours. The sessions included one where experts presented three alternative ethical positions concerning human-animal relations; an animal rights perspective, an animal welfare perspective and a more instrumental view of human/animal relations.

3. Xenotransplantation involves the transplantation of cells, tissues and organs from animals to humans. An EU funded-study, between 2009-2012 examined the responses of a variety of countries to the emergence of the xenotransplantation issue. This project focused, in particular, on the role played by citizen participation hence the title of the project 'Impact of Citizen Participation on Decision-Making in a Knowledge Intensive Policy Field' or CITPART for short ((Lang and Griessler, 2013; Griessler, Biegelbauer, Hansen, and Loeber, 2012; Griessler, Biegelbauer and Hansen, 2011). In actual fact, the use of participatory and deliberative devices (so-called Participatory Technology Assessment or PTA) to consider xenotransplantation has been extremely limited. Of the 12 countries studied in the CIT-PART project, only three - Canada, Switzerland and the Netherlands - used PTAs. In all three cases, the forums were set up at the behest of the respective health ministries. Six Citizen Forums of 15-25 demographically representative participants were set up in different Canadian regions (Einsiedel and Ross, 2002). In Switzerland, a PubliForum, consisting of 28 citizens selected to represent the Swiss population, met for eight days in 2000 (Griessler, 2011) whereas the PTA in the Netherlands was initiated in 1999 
The CIT-PART project examines actual real-world attempts to introduce deliberation into decision-making. This can be contrasted with deliberative exercises within civil society set up by academics. One such academic exercise concerned with the xenotransplantation issue, funded by the Wellcome Trust, consisted of a group of multi-disciplinary researchers grouped under the so-called Deliberative Mapping Project - which undertook, in 2002, the UK's first PTA in which xenotransplantation was assessed, along with alternatives, as a solution to the 'kidney gap'. The project mapped the views of four Citizens' Panels of 8-10 people, who met for six 90 minute sessions and a full day workshop together with a Specialists' Panel 17 strong, who engaged with the Citizens' Panels in a joint workshop (Eames, Burgess, Davies, Mayer, Staley, Stirling, Williamson, 2004: 13-15).

4. One way, suggested by Goodin $(2000 ; 2005 ; 2008: 51)$, of reconciling the impact of information provision with deliberative democracy is to employ the notion, mentioned earlier, that in these cases opinion change is a product of 'internal-reflective' processes of 'democratic deliberation within'.

5. Here it is interesting to note the debate the surrounds the notion of unnecessary suffering which is widely held to be the cornerstone of the animal welfare ethic, held to be the dominant frame within which the well-being of animals is considered. Facts alone cannot determine what 'unnecessary' suffering means because of the values that impinge upon competing interpretations. What is regarded as unnecessary will depend upon prior assumptions about the moral status of humans and animals. For example, some advocates of using animals in scientific research claim that even the remotest chance of scientific progress, particularly if it relates to medical progress, will justify inflicting, perhaps even severe, suffering on animals. For those who hold that the moral status of animals ought to be higher a much tougher definition of necessity must be provided before the infliction of suffering is justified. 


\section{References}

Barabas, J. (2004) 'How Deliberation Affects Policy Opinions', American Political Science Review, 98,4: 687-701.

Benhabib, S. (ed.) (1996) Democracy and Difference, Princeton, Princeton University Press.

Besson, J. And Marti, J. (eds.) (2006) Deliberative Democracy and its Discontents,

Aldershot, Ashgate.

Bohman, J. (1996) Public Deliberation: Pluralism, Complexity, and Democracy, Cambridge, MA: MIT Press.

Bohman, J. (1998) 'Survey Article: The Coming of Age of Deliberative Democracy', The Journal of Political Philosophy, 6, 4, 400-25.

Bohman, J. and Rehg, W. (eds.) (1997) Deliberative Democracy: Essays on Reason and Politics, Cambridge, MA, MIT Press.

Button, M. and Mattson, K. (1999) 'Deliberative Democracy in Practice: challenges and prospects for civic deliberation', Polity, 31, 609-37.

Chambers, S. (2003) 'Deliberative Democratic Theory’, Annual Review of Political Science, 6: $307-26$.

Cohen, J. (1986) ‘An Epistemic Conception of Democracy’, Ethics, 97, 1: 26-38.

Cohen, J. (1988) 'The Economic Basis of Deliberative Democracy', Social Philosophy and Policy, 6, 2: 25-50.

Cohen, J. and Rogers, J. (1993) 'Power and Reason' in A. Fung and E. Olin Wright (eds.) Deepening Democracy:Institutional Innovations in Empowered Participatory 
Governance, London: Verso: 237-55.

D’Arcy, S. (2007) 'Deliberative Democracy, Direct Action and Animal Advocacy', Journal for Critical Animal Studies, V, 2 web address.

D’Entreves, M. (ed.) (2002) Democracy as Public Deliberation: New Perspectives, Manchester, Manchester University Press.

Donovan, J. (2007) 'Attention to Suffering: Sympathy as a Basis for Ethical Treatment of Animals', in J. Donovan and C. Adams (eds.), The Feminist Care Tradition in Animal Ethics, New York: Columbia University Press.

Dryzek, J. (1987) Rational Ecology: Ecology and Political Economy, Oxford: Basil Blackwell.

Dryzek, J. (1990) Discursive Democracy: Politics, Policy and Political Science, Cambridge: Cambridge University Press.

Dryzek, J. (2000) Deliberative Democracy and Beyond: Liberals, Critics and Contestations, Oxford, Oxford University Press.

Dryzek, J. (2010) Foundations and Frontiers of Deliberative Governance, Oxford: Oxford University Press.

Eames M, Burgess J, Davies G, Mayer S, Staley K, Stirling A, Williamson S (2004) 'Xenotransplantation and its alternatives for addressing the 'kidney gap': a case study report from the deliberative mapping project' (http://discovery.ucl.ac.uk/98200/)

Eckersley, R. (1995) 'Liberal democracy and the Rights of Nature: the struggle for Inclusion, Environmental Politics, 4, 4, pp. 169-98.

Eckersley, R. (2000) 'Deliberative democracy, ecological representation and risk: Towards a democracy of the affected' in M. Saward (ed.) Democratic Innovation: Deliberation, 
Representation and Association' London: Routledge, pp. 117-32.

Einsiedel, E. and Ross, H. (2002) 'Animal Spare Parts? A Canadian Public Consultation on Xenotransplantation', Science and Engineering Ethics, 8, 579-91.

Elster J. ed. (1998) Deliberative Democracy, Cambridge: Cambridge University Press.

Elstub, S. (2014) 'Mini-publics: Issues and Cases' in S. Elstub, and P. McLaverty (eds.)

(2014) Deliberative Democracy: Issues and Cases, Edinburgh: Edinburgh University Press, pp. 166-88.

Elstub, S. And McLaverty, P. (eds.) (2014) Deliberative Democracy: Issues and Cases, Edinburgh: Edinburgh University Press.

Estland, D. (1997) 'Beyond Fairness and Deliberation: The Epistemic Dimension of Democratic Authority' in J. Bohman and W. Rehg, (eds.), Deliberative Democracy: Essays on Reason and Politics, Cambridge, MA, MIT Press: 173-204.

Fishkin, J. (2009) When the People Speak: Deliberative Democracy and Public Consultation, Oxford: Oxford University Press.

Fishkin, J. and Laslett, P. (eds.) (2008) Debating Deliberative Democracy, Chichester: John Wiley \& Sons.

Freeman, S. (2000) 'Deliberative Democracy: A Sympathetic Comment', Philosophy and Public Affairs, 29, 4: 371-418.

Friberg-Fernos, H. and Karlsson, S. (2014) 'The Consensus Paradox: Does Deliberative Agreement Impede Rational Discourse?', Political Studies, 62: 99-116.

Fung, A. (2003) 'Deliberation Before the Revolution: Toward an Ethics of Deliberative Democracy in an Unjust World', Political Theory, 33, 2: 397-419.

Gaus, G. (1997) 'Reason, Justification, and Consensus: Why Democracy Can’t Have it All' 
in J. Bohman and W. Rehg, (eds.), Deliberative Democracy: Essays on Reason and Politics, Cambridge, MA, MIT Press:205-42.

Goodin, R. (2000) 'Deliberation Within', Philosophy and Public Affairs, 29, 1, 81-109.

Goodin,R. (2003) Reflective Democracy, Oxford, Oxford University Press.

Goodin, R. (2005) 'Deliberation Within', Philosophy and Public Affairs, 29, 1, pp. 81-109.

Goodin, R. (2008) Innovating Democracy: Democratic theory and Practice after the Deliberative Turn, Oxford: Oxford University Press.

Griessler, R. (2011) 'Xenotransplantation Policy and Participatory Technology Assessment in Switzerland', Institute for Advanced Studies, Sociologial Series 95, Vienna.

Griessler, R. Biegelbauer, P. and Hansen, J. (2011) ‘Citizens’ Impact on KnowledgeIntensive Policy: introduction to a special edition, Science and Public Policy, 38, 8, 583-88.

Griessler, E. Biegelbauer, P. Hansen, J. and Loeber, A. (2012) Citizen Participation in Decision-Making on Complex and Sensitive issues. Experiences with Xenotransplantation, Report of the Project 'Impact of Citizen Participation on Decision-Making in a Knowledge Intensive Policy Field', Vienna, www.cit-part.at. Gutmann, A. (1996) 'Democracy, Philosophy and Justification' in S. Benhabib (ed.) Democracy and Difference, Princeton, Princeton University Press: 340-7.

Gutmann, A. and Thompson, D. (1996) Democracy and Disagreement, Harvard University Press: Cambridge Mass:.

Gutmann, A. and Thompson, D. (2004) Why Deliberative Democracy?, Princeton: Princeton University Press.

Habermas, J. (1990) Moral Consciousness and Communicative Action, Cambridge: Polity 
Press.

Habermas, J. (1996) Between Fact and Norms, Cambridge: Polity Press.

Hadley, J. (2015) ‘Animal Rights Advocacy and Legitimate Public Deliberation', Political Studies, 63: 696-712.

Hendriks, C. (2011) The Politics of Public Deliberation: Citizen Engagement and Interest Advocacy, Basingstoke: Palgrave Macmillan.

Humphrey, M. And Stears, M. (2006) 'Animal rights protest and the challenge to deliberative democracy', Economy and Society, 35, 3, pp. 400-22.

Kuper, R. (1997) 'Deliberating Waste: The Hertfordshire Citizens' Jury', Local Environment, 2, 2: 139-53.

Lafont, C. (2006) 'Is the Ideal of Deliberative Democracy Coherent?' in J. Besson, and J. Marti, (eds.) Deliberative Democracy and its Discontents, Aldershot, Ashgate, pp. 325.

Lang, A. and Griessler, E. (2013) Decision-Making on Complex and Sensitive Issues - A Case for Citizen Participation? Experiences with Xenotransplantation CIT-PART, Documentation of the Final Workshop, 12 June, 2012, Wein-Haus, Brussels.

Lukes, S. (2005), Power: A Radical View, Basingstoke: Palgrave Macmillan, 2nd edn. Luskin, R., Fishkin, J and Jowell, R. (2002) 'Considered opinions: Deliberative polling in Britain', British Journal of Political Science, 32, 3, pp. 455-87.

Macedo, S. (ed.) (1999) Deliberative Politics: Essays on Democracy and Disagreement, Oxford, Oxford University Press.

Mackie, G. (2006) 'Does Democratic Deliberation Change Minds?', Politics, Philosophy and Economics, 5, 3: 279-304. 
Medearis, J. (2005) ‘Social Movements and Deliberative Democracy Theory’, British Journal of Political Science, 35, 1: 53-75.

Miele, M., Veissier, I, Evans, A and Botreau, R. (2011) 'Animal Welfare: establishing a dialogue between science and society', Animal Welfare, 20, 103-117.

Mill, J.S. (1972) Utilitarianism, On Liberty, and Considerations on Representative Government. London: Dent.

Miller, D. (2002) 'Is Deliberative Democracy Unfair to Disadvantaged Groups?' in M. D’Entreves, (ed.) Democracy as Public Deliberation: New Perspectives, Manchester, Manchester University Press: 201-25.

Mutz,D. (2008) ‘Is Deliberative Democracy a Falsifiable Theory?', Annual Review of Political Science, 11, 521-38.

Nibert, D. (2002) Animal Rights, Human Rights: Entanglements of Oppression, Langham, Maryland: Rowman and Littlefield.

Niemeyer, S. (2004) 'Deliberation in the Wilderness: Displacing Symbolic Politics', Environmental Politics, 13, 2, 347-72.

O’Neil, J. (2002) 'Deliberative Democracy and Environmental Policy' in B. Minteer and B. Pepperman Taylor (eds.) Democracy and the Claims of Nature: Critical Perspectives for a New Century, Lanham MA: Rowman and Littlefield: 257-75.

Pettit, P. (1999) Republicanism: A Theory of Freedom and Government, Oxford: Clarendon Press.

Petts, J. (2001) 'Evaluating the Effectiveness of Deliberative Processes: Waste Management Case Studies', Journal of Environmental Planning and Management, 44, 2, 207-26. Regan, T. (1984) The Case for Animal Rights, London: Routledge. 
Rosenberg, S. (2014) 'Citizen Competence and the Psychology of Deliberation' in S. Elstub, and P. McLaverty (eds.) (2014) Deliberative Democracy: Issues and Cases, Edinburgh: Edinburgh University Press, pp. 98-117.

Ryfe, D. (2005) 'Does Deliberative Democracy Work?', Annual Review of Political Science, $8,49-71$.

Sanders, L. (1997) ‘Against Deliberation’, Political Theory, 25, 3: 347-76.

Saward, M. (ed.) (2000) Democratic Innovation: Deliberation, Representation and Association' London: Routledge.

Shapiro, I. (1999) 'Enough of Deliberation' in S. Macedo, S. (ed.) Deliberative Politics: Essays on Democracy and Disagreement, Oxford, Oxford University Press: 28-38.

Shapiro, I. (2005) The State of Democratic Theory, Princeton: Princeton University Press.

Sharpe, R. (1988) The Cruel Deception: The Use of Animals in Medical Research. Wellingborough: Thorsons.

Simon, W. (1999) 'Three Limitations of Deliberative Democracy: Identity Politics, Bad Faith and Indeterminacy' in S. Macedo (ed.) Deliberative Politics: Essays on Democracy and Disagreement, Oxford: Oxford University Press: 49-57.

Singer, P. (1990) Animal Liberation, second edition, London: Cape.

Smith, G. (2003) Deliberative Democracy and the Environment, London: Routledge.

Smith, W. (2004) 'Democracy, Deliberation and Disobedience', Res Publica, 10: 353-77.

Steirner, J. (2008) 'Concept Stretching: The Case of Deliberation', European Political Science, 7: 186-90.

Sunstein, C. (2008) ‘The Law of Group Polarization' in J. Fishkin, J. and P. Laslett (eds.) Debating Deliberative Democracy, Chichester: John Wiley \& Sons: 80-101.

Talisse, R. (2005) 'Deliberativist responses to activist challenges: A continuation of Young's 
dialectic', Philosophy and Social Criticism, 31, 4: 423-44.

Thompson, D. (2008) 'Deliberative Democratic Theory and Empirical Political Science', Annual Review of Political Science, 11: 497-520.

Torres, B. (2007) Making a Killing: The Political Economy of Animal Rights, Oakland, CA: AK Press.

Young, I. (1996) 'Communication and the Other: Beyond Deliberative Democracy' in S. Benhabib (ed.) Democracy and Difference, Princeton, Princeton University Press: $120-35$.

Young, I. (2000) Inclusion and Democracy, Oxford: Oxford University Press.

Young, I. (2001) 'Activist Challenges to Deliberative Democracy', Political Theory, 25, 5: 670-90.

Walzer, M (1999) 'Deliberation and What Else?' in S. Macedo (ed.) Deliberative Politics: Essays on Democracy and Disagreement, Oxford: Oxford University Press: 58-69. 